\title{
DRUG PROFILE
}

\section{Esketamine Nasal Spray}

\author{
Mohamed SJ Farhana ${ }^{1}$, Subbarayan Dhivagar ${ }^{2}$, Subramaniyan Prabavathy ${ }^{3}$
}

\begin{abstract} Keywords: Esketamine, Nasal spray, Treatment-resistant depression.

Pondicherry Journal of Nursing (2020): 10.5005/jp-journals-10084-12137

\section{INTRODUCTION}

Esketamine is the s-enantiomer of ketamine. Nasal spray is a fast-acting drug. It can be used to treat the treatment-resistant depression. Esketamine was approved by the FDA on March 5, 2019, to treat depression. Unlike other oral antidepressants, which often take 4- 6 weeks to show their effectiveness, Esketamine nasal spray is effective within hours. Due to rapid absorption, the drug will be administered through nasal spray. ${ }^{1}$
\end{abstract}

Esketamine is the newer drug in psychiatry with high efficacy. Esketamine (s-enantiomer of ketamine) was approved by the FDA on March 5, 2019, to treat treatment-resistant depression. Esketamine is delivered through nasal spray. Nasal spray is the fast-acting drug. It can be used to treat treatment-resistant depression. Each device contains $28 \mathrm{mg}$. Esketamine increases dopamine activity in the brain. It is contraindicated for patient with aneurysmal vascular disease, arteriovenous malformation, intracerebral hemorrhage, children, pregnant mothers, and lactating mothers.

\section{Brand Name}

- Ketanest

- Spravato

\section{DosAge}

\section{Induction Phase}

Weeks 1-4

- Nasal spray can be administered for the duration of twice per week.

- First day starting dose will be $56 \mathrm{mg}$ and the subsequent doses: $56 \mathrm{mg}$ or $84 \mathrm{mg}$.

\section{Maintenance Phase}

\section{Weeks 5-8}

- Nasal spray should be administered once in a week (56 mg or $84 \mathrm{mg}$ ).

\section{Week 9 and after}

- Administer the spray twice or once in a week; individualize dosing frequency to the least frequent dosing to maintain remission/response.

- Fifty six mg or 84 mg.

\section{Storage}

Store the drug at the temperature of $20-25^{\circ} \mathrm{C}\left(68-77^{\circ} \mathrm{F}\right)$; and the excursion is permitted at the temperature of $15-30^{\circ} \mathrm{C}\left(59-86^{\circ} \mathrm{F}\right) .^{2,3}$

\footnotetext{
${ }^{1-3}$ Department of Mental Health Nursing, Kasturba Gandhi Nursing College, Puducherry, India
}

Corresponding Author: Mohamed SJ Farhana, Department of Mental Health Nursing, Kasturba Gandhi Nursing College, Puducherry, India, Phone: +91 7708524115, e-mail: jasminemscnsg26@ gmail.com

How to cite this article: Farhana MSJ, Dhivagar S, Prabavathy S. Esketamine Nasal Spray. Pon J Nurs 2020;13(1):13-15.

Source of support: Nil

Conflict of interest: None

\section{INDICATION}

- Major depressive disorder

- Treatment-resistant depression

- Depression

\section{Contraindication}

- Aneurysmal vascular disease

- Arteriovenous malformation

- Intracerebral hemorrhage

- Stroke

- Heart attack

- Brain injury

- Children

- Pregnant mothers

- Lactating mothers

- Hypersensitivity

\section{Pharmacodynamics}

Esketamine, the s-enantiomer of racemic ketamine, is a nonselective, noncompetitive $\mathrm{N}$-methyl-D-aspartate (NMDA) receptor antagonist (NMDA is an ionotropic glutamate receptor). Research evidences has shown that esketamine increases the dopamine level in the brain. But exact mechanism is unknown. ${ }^{4,5}$

(-) The Author(s). 2020 Open Access This article is distributed under the terms of the Creative Commons Attribution 4.0 International License (https://creativecommons. org/licenses/by-nc/4.0/), which permits unrestricted use, distribution, and non-commercial reproduction in any medium, provided you give appropriate credit to the original author(s) and the source, provide a link to the Creative Commons license, and indicate if changes were made. The Creative Commons Public Domain Dedication waiver (http://creativecommons.org/publicdomain/zero/1.0/) applies to the data made available in this article, unless otherwise stated. 

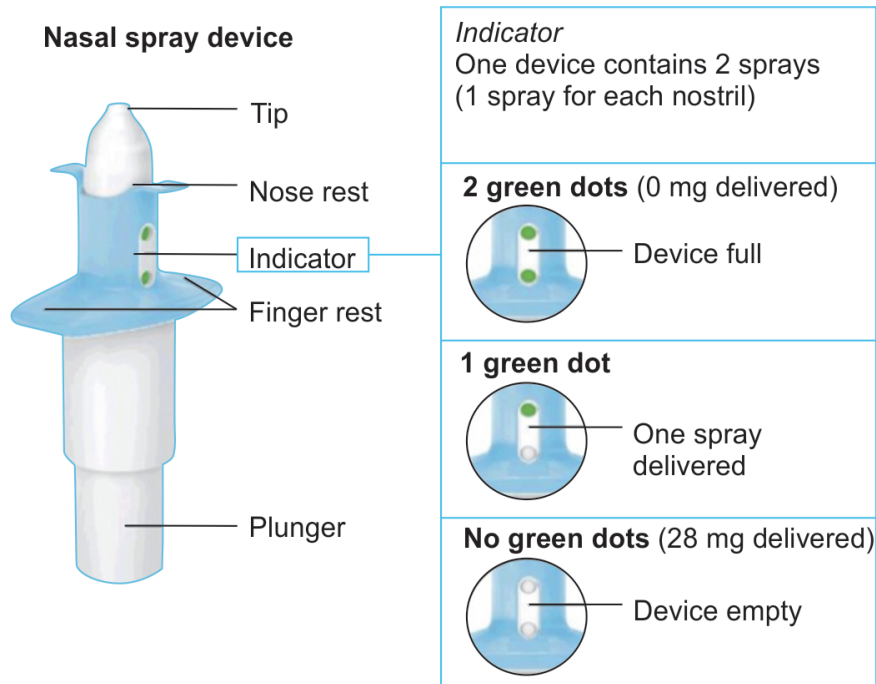

Fig. 1: Nasal spray device

\section{Pharmacokinetics}

Due to rapid absorption, this drug can be administered through nasal spray. The mean absolute bioavailability is approximately $48 \%$ after administration of esketamine nasal spray. The peak plasma concentration will be achieved within 20-40 minutes. It is excreted in urine: $<1 \%$ and in feces: $\leq 2 \%$ metabolites (Fig. 1). ${ }^{6}$

\section{HALF-LIFE}

The mean terminal half-life is $7-12$ hours.

\section{Side Efrects}

\section{Common Side Effects}

- Disassociation

- Dizziness

- Nausea

- Sedation

- Vertigo

- Decreased feeling

- Palpitation

- Hypertension

\section{Severe Side Effects}

- Drowsiness

- Changes in mood or behavior

- Worsening depression

- Hallucination

- Suicidal thought or behavior

\section{Drug Interactions}

Esketamine should not be administered with other drugs like amphetamines, antianxiety medications, monoamine oxidase inhibitors, opioids pain medications, seizure medications, sedatives, and tranquilizers.

\section{Nurses Responsibilities Patient Preparation}

- Check the blood pressure of the patient before administering the drug. If the patient blood pressure is raised, a decision should be taken to delay the drug administration.

- Instruct the patient to blow nose before administering the first dose.

- Instruct the patient if they are self-administering the drug; inform the patient to follow instruction in the wrapper.

- Instruct the patient not to take food before 2 hours.

- Instruct the patient not to drink any liquid before 30 minutes.

\section{Post-administration Observation}

- Monitor the patient for at least hours the patient is safe to leave.

- Monitor blood pressure of the patient for 40 minutes after the administration of the drug.

- Refer patients immediately for emergency care if the patient is experiencing any of this symptoms of a hypertensive crisis, like chest pain or shortness of breath, or hypertensive encephalopathy like sudden severe headache, visual disturbances, seizures, diminished consciousness, or focal neurological deficits.

- Closely monitor blood pressure of the patient for half an hour.

- Instruct the patients not to engage in potentially hazardous activities like driving a motor vehicle or operating machinery after administering the nasal spray.

\section{Missed Drug Sessions}

- Instruct the patient to take drug correctly. If they missed the dose it will worsen. ${ }^{7}$

\section{References}

1. Molero P, Ramos-Quiroga JA, Martin-Santos R, et al. Antidepressant efficacy and tolerability of ketamine and Esketamine: a critical review. CNS Drugs 2018;32(5):411-420. DOI: 10.1007/s40263-018-0519-3. 
2. Andrade C. Ketamine for depression, 4 : in what dose, at what rate, by what route, for how long, and at what frequency? J Clin Psychiatry 2017;78(7):e852-e857. DOI: 10.4088/JCP.17f11738.

3. Bahr R, Lopez A, Rey JA. Intranasal Esketamine (Spravato ${ }^{T M}$ ) for use in treatment-resistant depression in conjunction with an oral antidepressant. P T 2019;44(6):340-375.

4. Canuso CM, Singh JB, Fedgchin M, et al. Efficacy and safety of intranasal Esketamine for the rapid reduction of symptoms of depression and suicidality in patients at imminent risk for suicide: results of a double-blind, randomized, placebo-controlled study. Am J Psychiatry 2018;17(1):620-630. DOI: 10.1176/appi.ajp.2018.17060720.
5. Walker ER, McGee RE, Druss BG. Mortality in mental disorders and global disease burden implications: a systematic review and meta-analysis. JAMA Psychiatry 2015;72(4):334-341. DOI: 10.1001/ jamapsychiatry.2014.2502.

6. Rush AJ, Trivedi MH, Wisniewski SR, et al. Acute and longer-term outcomes in depressed outpatients requiring one or several treatment steps: a STAR*D report. Am J Psychiatry 2006;163(11): 1905-1917. DOI: 10.1176/ajp.2006.163.11.1905.

7. World Health Organization, Media Centre, Depression Fact Sheet, Updated 22 March. 2018. Accessed December 26, 2018. 